\title{
Letter to the Editor: regarding "Lipomatous ependymoma: report of a rare differentiation pattern with a comprehensive review of literature"
}

\author{
Metin Dogan' ${ }^{1}$ İsmail Okan Yildirim ${ }^{1}$ Derya Gumus Dogan ${ }^{2}$
}

Received: 25 March 2016/Accepted: 19 April 2016/Published online: 5 July 2016

(C) The Japan Society of Brain Tumor Pathology 2016

Keywords Lipomatous $\cdot$ Ependymoma $\cdot$ Brain

\section{Dear Editor,}

We read with great interest the case report titled "Lipomatous ependymoma: report of a rare differentiation pattern with a comprehensive review of literature" authored by Kavita Gaur published in the February 2016 issue of Brain Tumor Pathol [1]. In this case report, a "13-year-old girl presenting with left-sided hemiparesis altered sensorium and episodic headache with bouts of projectile vomiting" was described. The authors have expressed that a large heterogeneous intraventricular mass lesion displaying focal calcification and hyperintensity on T1- and T2weighted fluid attenuated inversion recovery (FLAIR) magnetic resonance images suggested the presence of intratumoral fat. Herein, we demand a correction, in case your readers may be misled by a technical problem. The image which is presented in Fig. 1a as a T1-weighted image is a FLAIR magnetic resonance image, because vasogenic edema surrounding the mass effect in the parenchyma of the right lateral ventricle is hyperintense in
Fig. 1a. In T1-weighted images, vasogenic edema is hypointense. Evaluating brain parenchyma and ventricular images together also shows that this is a FLAIR-weighted sequence instead of a T1-weighted sequence. We thought that this mistake is a wrong message given to the readers of your journal, most of whom are not radiologists.

Yours respectfully

Metin Dogan

Ismail Okan Yildirim

Derya Gumus Dogan

Compliance with ethical standards

Conflict of interest There is no conflict of interest.

\section{Reference}

1. Gaur K, Batra VV, Gupta R, Sharma MC, Narang P, Pandey PN (2016) Lipomatous ependymoma: report of a rare differentiation pattern with a comprehensive review of literature. Brain Tumor Pathol. doi:10.1007/s10014-016-0253-9
This comment refers to the article available at doi:10.1007/s10014016-0253-9.
Derya Gumus Dogan

deryagumus@yahoo.com

1 Department of Radiology, Inonu University School of Medicine, Malatya, Turkey

2 Department of Developmental Behavioral Pediatrics, Inonu University School of Medicine, 44280 Malatya, Turkey 